\title{
Object transfers: an embodied resource to progress joint activities and build relative agency
}

\begin{abstract}
This article builds on ethnomethodological, conversation analytic research on object transfers: how participants hand over objects to one another. By analyzing video recordings of mundane (cars) and institutional interactions (laboratories), we focus on situations where an object is central to and talked about in the joint course of action. We focus on different organizations of object transfer and show that one embodied move is decisive, either a sequentially implicative 'give' or an arm extension designed as a stand-alone 'take'. We examine the interrelationship between the organization of the object transfer and the broader course of action (e.g. request or offer sequence), which is either overlapping or intersecting. We demonstrate that by making the decisive move, either the participant initially holding the object or her recipient critically influences the progression and trajectory of the activity, and displays agency.
\end{abstract}

\section{Keywords}

Ethnomethodology; Conversation Analysis; Multimodal interactions; Objects in interaction; Object transfers; Agency.

Sylvaine Tuncer

Department of Computer and Systems Sciences

Stockholm University

Postbox 7003

16407 Kista, Sweden

+46(0)737078748

sylvaine@dsv.su.se

Pentti Haddington

English Philology, Faculty of Humanities

University of Oulu

P.O.Box 8000

FI-90014 University of Oulu

+358 (0)294 483285

Pentti.haddington@oulu.fi

This article has been published in a revised form in Language in Society https://doi.org/10.1017/S004740451900071X. This version is free to view and download for private research and study only. Not for re-distribution, re-sale or use in derivative works. 


\section{INTRODUCTION $^{1}$}

The various environments we navigate in our daily lives are all laden with objects. Further, the way we use and arrange these many objects creates social and inhabited worlds. Therefore, our ability to build together a shared perspective on and knowledge of the material world around us is integral to our attempts to relate to each other in the here-and-now, to communicate, and to act together in a coherent and constructive fashion.

This article studies object transfers, a commonplace event in interaction in which an object moves from one participant's hand(s) to another's. It focuses both on situations where the object is the focus of the interactional moment (see Tuncer et al. forth.) and on emergent courses of action where the transfer is not necessarily expected. The analysis targets the participants' embodied conduct with the object in relation to the emergent course of action. We show that the moment and the manner in which the object is made available or proffered, and when it is taken hold of, are crucial in progressing the course of action and building participants' relative agency in the activity. In other words, one participant "does more" for the transfer to happen, and with this move she progresses, influences, and displays her agency in the joint course of action. Thus, object transfer is a meaningful and flexible resource for participants to talk about objects in face-to-face interaction.

We use the neutral term 'object transfer' instead the many vernacular terms referring to the same phenomenon, such as to give, offer, grant, take, take away, distribute, borrow, hand over, and so on. The latter are problematic because they tend to a priori ascribe action types and convey social meanings and values to the action (Valsiner, 2000). Besides the fact that the expression 'object transfer' has been used in prior ethnomethodological conversation analytic research (EMCA), it also allows us to analyze the action whereby the object changes hands independently from the broader course of action, i.e. a request or offer sequence. It also allows us to unpack the series of actions before and after the transfer. It provides the possibility to locate the transfer within the request or offer sequence and analyze its import for it. In other words, the term 'object transfer' is operative in, and supports, our theoretical and analytic approach of action as emergent and collaborative.

In EMCA research on multimodal interactions (Deppermann 2013), which focuses its analysis on talk, embodied action and any sensory fields relevant to participants and amenable to study, there has been a growing interest in objects in interactions (for an outline of research, see Nevile et al. 2014). An early example is Streeck's (1996) analysis of the various semiotic functions and meanings business persons can afford biscuit packages during a negotiation. More recently, Fox and Heinemann (2015) show how customers and shoetenders, at the beginning of service encounters, orient to and manipulate the shoe to produce different types of requests in an economy of means. Ekström \& Lindwall (2014) show the way craft teachers and their students diagnose and remediate mistakes by talking about, orienting to and manipulating pieces of fabric. Finally, Fasulo \& Monzoni (2009) focus on designers assessing clothes and planning future work in a fashion atelier through talk, deictic practices and manipulations. This strand of studies has begun to provide new perspectives on how objects become part of socially meaningful environments in the course of temporally-unfolding, joint activities, and through methodic practices.

Audiences beyond EMCA may be interested in how participants orient to and produce a material world in common in real episodes of professional and ordinary life. This study touches upon the emergence of human sociality in communication, through objects as mediations. The notion of 'mediation', originally from actor-network theory (Latour 1993) and science and technology studies (Knorr-Cetina 1997), refers to the processual, mutual constitution of relations and ontologies. Our study complements this perspective with an ethnomethodological attention to the detailed accomplishment of 
lived courses of action. By focusing on how participants interact about objects and hand them over to one another, it sheds light on the formation of human sociality as embedded in material environments.

Handing over objects can be part of rituals, such as gift-giving in birthday celebrations (Robles, 2012), where the act stands as a symbol of the social relationship. In everyday life, we tend to not even notice the innumerable occasions we hand over objects. This partly explains why object transfers are touched upon in a variety of studies, as part of other processes. In Kendrick \& Drew's (2016) programmatic categorization of recruitment and assistance practices, several examples involve the transfer of objects such as a box of matches, a lip moisturizer or a drinking glass. Object transfers also typically occur, as is also evident in the present study, in sequences involving requests for and offers of objects. They have been extensively studied in various domestic settings (Dixon 2015; Ogiermann, 2015a, 2015b; Rauniomaa \& Keisanen 2012; Zinken \& Ogiermann 2013), some of them through multimodal analysis. As part of the latter, Zinken (2015) shows that 'Can I have X?' requests are used in situations where the addressee has momentary control over the object, so that her cooperation is required for the object to become available to the requester, while the requester displays a high entitlement to obtain the object. Zinken emphasizes that the request can be reinforced with an arm stretch towards the object, and is systematically responded to with a non-verbal action making the object accessible. Rossi (2014) focuses on the circumstances in which objects can be offered or requested through embodied means only or also using talk. The study distinguishes as a main variable whether the action to be performed with the object is projectable as part of a joint course of action, or contingent, a point we discuss further below.

Video-based research on object transfers as the focus phenomenon is relatively rare, except in surgical theatres and hair salons, two professional settings involving tools, and in interactions involving children. Transferring an object has indeed proven a conspicuous phenomenon to study joint attention and socialization processes in interactions involving children (Jones \& Zimmermann 2003; Kidwell \& Zimmermann 2007; Lerner \& Zimmermann 2003; Scollon 2001; Takada \& Tomoko 2015; Wootton 1994). For example, Kidwell \& Zimmermann (2007) analyze different interactional trajectories, such as showing, offering, requesting or giving, which children can initiate by proffering an object to another participant and creating joint attention to it. Unpacking how children coordinate their manual actions to hand over an object, Kidwell (2013) analyses a young child's successive attempts, trials and errors, in giving a toy to a crying peer, in a broader project to comfort him. Kidwell describes recognizable practices, such as the object being proffered towards eye and/or hand region; the giver (mis)projecting the moment where she can release the object; or controlling through touch that the taker has indeed grasped the object that is put in his hand. Finally, Lerner \& Zimmermann (2003) show that children can rely on the ambiguity of an object proffer to gently trick their peers. By retrieving the object before the co-participant can take it, a child skillfully turns the recognizability of action into an appearance of action. The authors thereby raise the interesting problem of action ascription inherent to joint orientation to tangible objects. The present article builds on these issues, in particular the methods associated with the handling of objects, and the processes of action ascription within larger sequences of action and interactional projects. However, the above studies concerning children cannot be generalized to all forms of interactions, especially with showing and giving being far from mutually exclusive actions.

The exchange or passing of instruments has also been studied in professional settings, especially in surgical theatres (Bezemer, Murtagh, Cope, Kress, \& Kneebone 2011; Heath, Sanchez-Svensson, \& Nicholls 2018; Korkiakangas, Weldon, Bezemer, \& Kneebone 2014; Sanchez-Svensson, Heath, \& Luff 2007). These studies show that passing an instrument is a critical action during a surgical procedure, on whose achievement the procedure's smooth progression depends. They show that team members give or take objects at specific moments, often without verbal requests or offers (Hindmarsh \& Pilnick 2007). Surgical procedures provide for the projectability of action, so that the ability to anticipate next actions 
is part of professional competence. While the exact timing of the object transfer is not determined, practitioners proffering and holding an empty hand palm upward, for example, are commonly understood as requesting a specific object, and responded to with the right object put in their hand. This point resonates with Rossi's (2014) emphasis on whether the action to be performed with the object is projectable as part of a joint course of action, or contingent, as a main variable influencing whether the request is produced through embodied means only or also using talk. Besides, each surgical instrument is presented in a way that makes it easy for the recipient to take the object and use it right away. SanchezSvensson et al. (2007) also show that instruments are positioned on the table so as to facilitate their successive transfers: the environment is institutionally prepared for transfers which are part and parcel of the procedure. Finally, Horlacher (2019) analyses how hand-held mirrors are passed from apprentices to hairdressers in hairdressing salons. Building on the relationship between professional competence and the projectability of procedures, the study sheds light on how object transfers can contribute to producing workplace asymmetries between apprentices and hairdressers.

Our focus is on the more or less progressive emergence of an object transfer, and more specifically on when and how the transfer is achieved in relation to the progression of the request or offer sequence. We show that these elements have important, interpersonal consequences since the participant making a decisive move to prompt and progress the transfer displays particular agency in the ongoing course of action. Second, we focus on situations where participants are involved in a joint course of action in which the object plays a central role. These are called 'object-centered sequences' ${ }^{2}$ A few existing studies make a distinction between them and 'object-implicating interactions' (e.g., Weilenmann \& Lymer, 2014). In the latter, objects feature as resources for interaction, most often as tools or commodities, but the object is not discussed in itself. In 'object-centered sequences', on the other hand, participants talk about objects' qualities, their status for the participants, or their potential uses in the here-and-now. In brief, objects are made accountable for the situation (Hindmarsh \& Heath 2000). Due to this strong involvement with and triadic orientation to objects, transfers have a particular interactional import in object-centered sequences. Our analyses therefore do not include transfers occurring in objectimplicating interactions.

\section{DATA AND METHOD}

The data are video recordings of mundane and institutional interactions from two corpora. The first is a corpus of interactions in cars among family members, friends and work colleagues collected in Britain (15 hours), and the second a corpus from a biochemistry laboratory in Finland ( 97 hours). The languages used are British English (car corpus), Finnish, French, and English as a Lingua Franca (laboratory corpus). Starting with a total collection of 99 object transfers, we selected instances occurring in objectcentered sequences (see above). We transcribed and systematically analyzed a final collection of 30 video clips (19 in the lab, 11 in cars) in which 47 object transfers occur. The data were transcribed following Jeffersonian conventions for talk (Jefferson 2004) and Mondada's conventions for embodied conduct (Mondada 2018). ${ }^{3}$ In the transcript and the analyses, 'A' refers to the participant initially holding the object, and 'B' to the co-participant to whom the object is transferred. When the data are in Finnish or French, the original talk and a translation (in bold and italics) are provided on separate lines. In the Finnish excerpt (Excerpt 1), a morpheme gloss is provided below the original talk. The data were analyzed following the principles of Conversation Analysis (Schegloff 2007; Schegloff \& Sacks 1973), including the whole range of semiotic resources participants may use, such as talk, body orientation, gaze, gestures, mobility and the material environment (Deppermann, 2013; Goodwin 2000; Streeck, Goodwin \& LeBaron 2011), transcribed in grey font. 


\section{GOALS AND CONTRIBUTIONS OF THE PRESENT STUDY}

The use of different data sets in this paper both demonstrates the generalizability of the findings and sheds light on specific situated activity systems (Goodwin 1997). We will show, for example, that the moment a scientist takes an object to inspect it can indicate and display immediate alignment in a collaborative project with the object or, conversely, a delayed understanding of the colleague's request. As for family members in the car, similar practices can display involvement in a joint, pedagogical activity with food packages, or display the driver and front-seat passenger's shared awareness of drivingrelated matters. In other words, the methods we identify are used in activities and situations that produce different types of interpersonal and/or organizational relationships, rights and obligations, and activityrelated categories, in and of themselves revealing of distinct social worlds. Finally, the use of two different corpora allows us to investigate participants' physical resources and constraints depending on their material environment (LeBaron \& Streeck 1997). For example, the work of lab scientists fundamentally relies on visible action and mutual monitoring, whereas participants in the car have a limited shared visual space, and manual coordination is sometimes achieved through touch.

By focusing the analysis on the placement and design of object transfers, we make the following two arguments. First, we show that different embodied moves involving the object can be decisive for the transfer to happen: either A can proffer the object that is responded to as a 'give' by B, or B can selfinitiate the 'taking' of an object which A has previously made available. In other words, certain moves with the object are sequentially implicative; they make relevant particular subsequent embodied actions involving the object. The analysis is organized so as to constitute a continuum starting from the former and ending with an example of the latter. Thus, we show that one participant "does more" to make the transfer possible; she actively progresses the joint course of action and enacts her agency in it.

Second, and throughout the analyses, we explore the interconnection between the organization of the object transfer and concurrent action sequences (e.g. request and offer sequences) of which the object transfer is a part, as two partly independent but interrelated organizations. While transfers that follow proffers immediately tend to index participants' alignment in an unproblematic course of action, and especially the recipient's compliance to the initiation of action sequence, the less responsive the object transfer, the more its organization intersects with the progression of the action sequence. In other words, the participant "doing more" for the object transfer simultaneously displays agency to make a substantial move in the progression of the action sequence. These two arguments are inseparable, and we address them together throughout the analytic section.

The analysis is organized as follows. The first empirical section focuses on instances where the participant initiating the request/offer sequence also initiates the transfer, resulting in an overlap of both organizations. We show that the recipient can also resist A's project by not taking the object. In the second empirical section, we focus on situations where the sequence and the transfer are not initiated by the same participant. Then, we show that the move making the object available can be shaped and treated as more or less sequentially implicative, and that either form enacts different distributions of agency. The final section focuses on instances where, again, the participant initiating the action sequence does not initiate the transfer, but where transfer initiation overlaps with that of the sequence in ways that reflect and contribute to resolve emerging breaches in intersubjectivity. 

RECIPIENT ALIGNS OR RESISTS

Excerpt 1 involves two researchers in the biochemistry lab. Just prior to the beginning of the excerpt, B has entered the lab where A has been inspecting a tube from various angles. A has started complaining about some unexplained residue in a series of tubes, to which B displays recipiency through gaze and vocal continuers. At the outset of Excerpt 1, A is turning his back to B.

\section{Excerpt 1 (Biochemistry Lab corpus)}

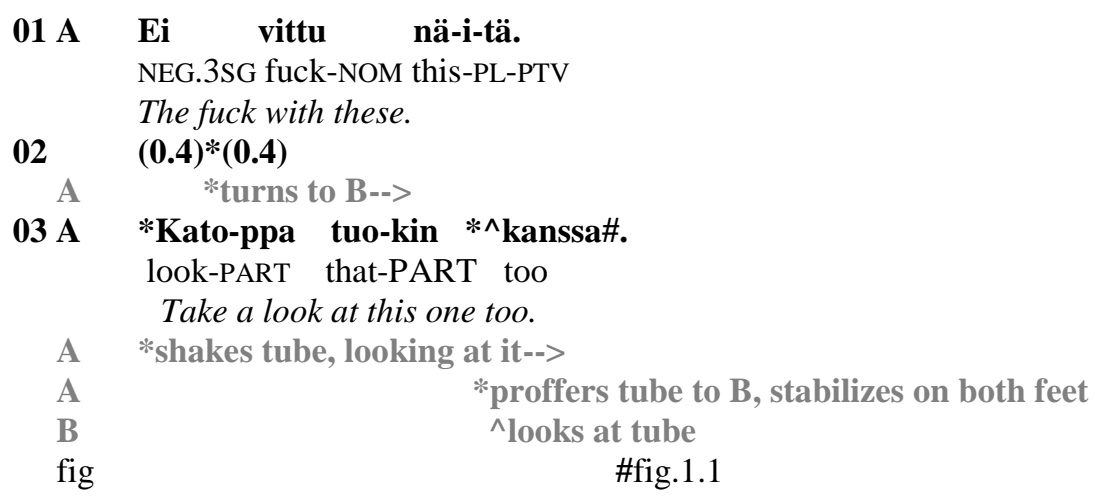

04 B B

05 A $\mathbf{A}$ B fig $(0.3)^{\wedge}(0.7)^{\wedge}(0.2)$

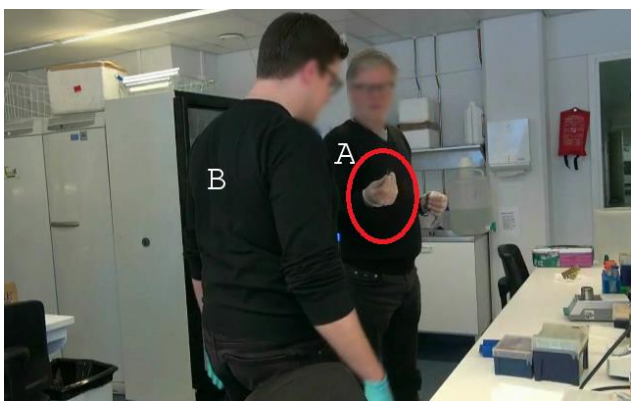

Figure 1.1

$\wedge$ raises arm to tube

${ }^{\wedge}$ hand on tube

Sul-la on \#*paremma-t silmä-t. ${ }^{\wedge}$

you.1SG-ADE be.3SG better-PL eye-PL

You have better eyes.

*releases tube, looks away

\#fig.1.2

$\wedge$ turns away with tube in hand, looking at it 
06

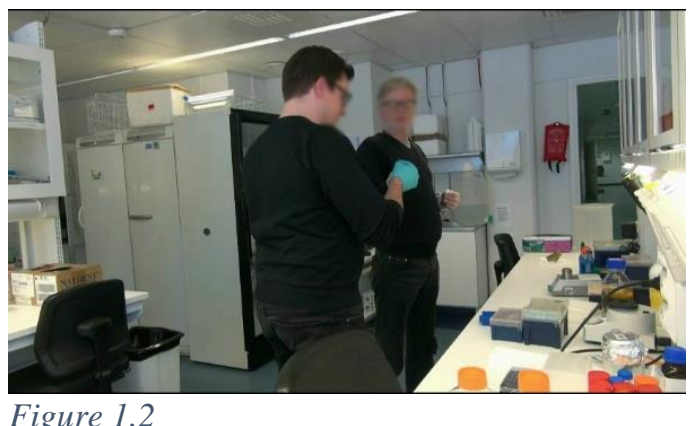

(3.0)

07 B Ehkä täällä jotain on vielä täällä pilli-n --

Maybe here something be-3SG still here tube-GEN

Maybe there is still something here in the tube.

A dismisses the previous topic ("The fuck with these", 1. 1) and turns to B, holding the microtube in front of him and looking at it. He then initiates talk about it with "Take a look at this one too." (1. 3). This multimodal move creates joint attention to the object (see Tuncer \& Haddington forth.): B turns his gaze to the tube after "take a look at this one". A stops in a position where the microtube is physically accessible to B, in a kind of proffer (Figure 1.1), after which B extends his arm to take the tube. While the tube goes from A's hand to B's hand (Figure 1.2), A accounts for requesting B's contribution, soliciting his visual acuity to discern aspects of the object ("You have better eyes.", 1. 5). As soon as B has taken hold of the tube, he turns around, lifts it up and inspects it silently for three seconds. He then responds to A with a candidate description and assessment of the object: "Maybe there is still something here in the tube." (1. 7).

The object's trajectory in space is also critical in the emergence and joint achievement of the transfer: A progressively moves it from his side, to the space between him and B, and closer to B mid-way between his hand and eye regions. Since 'highlighting and positioning for perception' is a recurrent practice in biochemistry and typical of professional vision (Goodwin, 1994), B understands and responds to A's proffer and directive 'to look' at the microtube as a request to take the object for inspection. By responding and taking the object at this precise moment, B aligns with A's interactional project and becomes involved in the new course of action. The object transfer and the request sequence are initiated at the same time and also mark an upgrade of joint involvement. A initiates both the request sequence and the transfer; B takes the object and aligns. In this example, the organization of the object transfer overlaps with that of the action sequence (request-compliance) which thereby progresses unproblematically.Excerpt 2 comes from the car corpus. While the initiation of the object transfer and the initiation of the request sequence overlap, in this example the object transfer does not occur. Prior to the excerpt, the child (A) sitting in the front seat has been eating a bun, and during a short lapse in the conversation he can be heard to be chewing it. His mother (B) is driving and looking at the road.

\section{Excerpt 2 (Habitable Cars corpus)}

$\begin{array}{ll}\text { 01 A } & \text { Mummy (.) *this goes cra: }: \text { ck. } \\ \text { A } & \\ \text { 02 } & \text { *partly turns upper body towards B } \\ \text { 03 A } & \text { And I don't like tha:t (ugly bits), (that's) the pi:ps. } \\ 04 & (1.5) \\ \text { 05 B } & { }^{\circ} \text { Is it. } \\ \text { 06 } & \text { (0.9) } \\ \text { 07 A } & \text { Y::eah. }\end{array}$




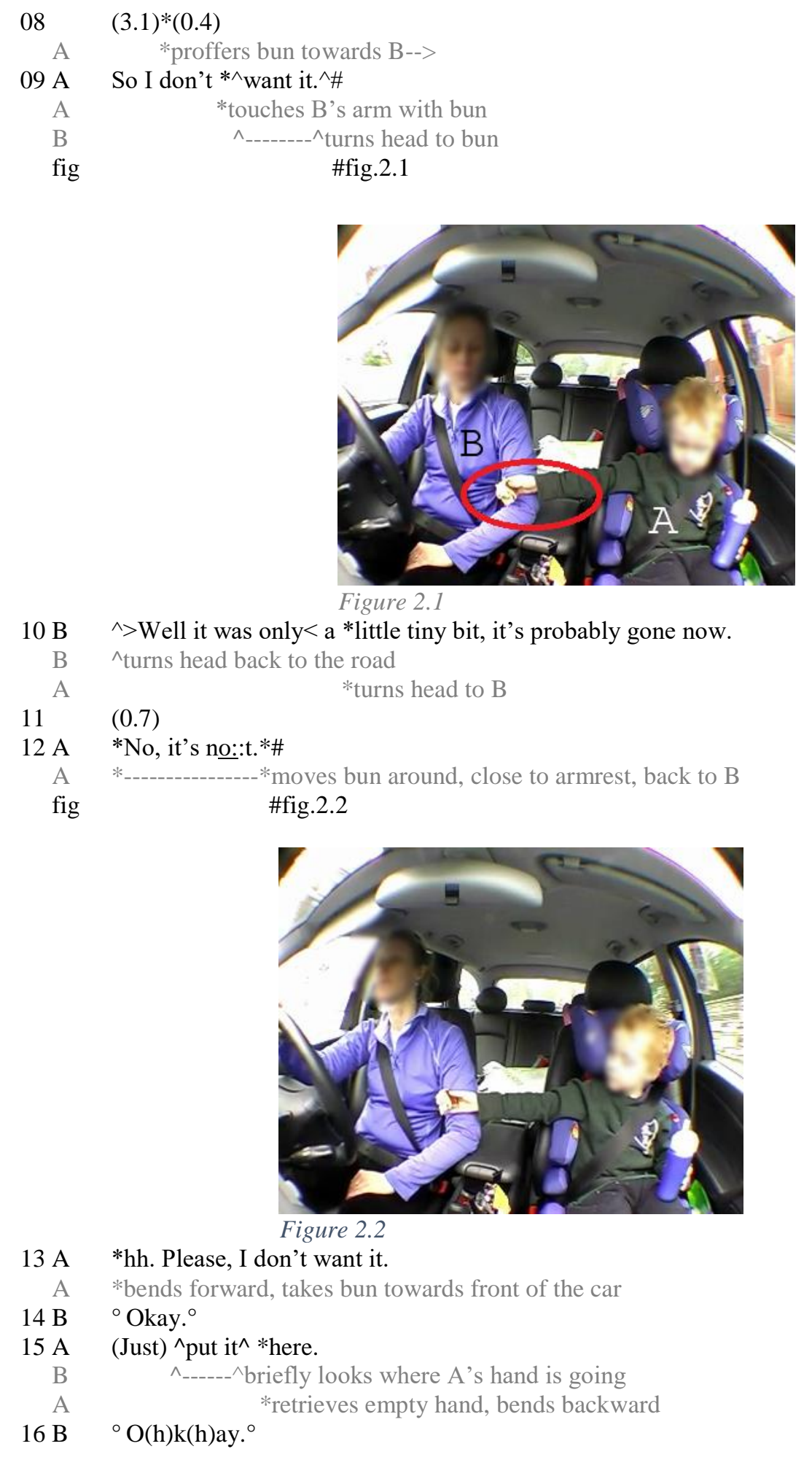

With "Mummy (.) this goes cra:ck. (0.5) And I don't like tha:t (ugly bits), (that's) the pi:ps." (lines 1-3), A initiates a complaint about his bun. 1.5 seconds later, B's request for confirmation "Is it." (1. 5) can be heard as an off-record practice to pursue an account (Raymond \& Stivers 2016), an expansion-eliciting question (Steensig \& Heinemann 2013) treating the just prior turn as expandable and pursuing further 
unpacking. A first merely confirms ("Y::eah.", 1. 7), and about three seconds later, he extends his arm holding the bun towards B (Figure 2.1), and elaborates with "So I don't want it." (1. 9). During the turn, his hand touches B's arm in order to make her feel his proffer through touch (Nishizaka 2011; Cekaite 2015), which displays his awareness that she is focusing her gaze on the road. Following the complaint, the proffer and elaboration are hearable as a rejection of the bun and a request for B to take it.

Soon after the bun has touched her arm, B turns her head to it (Figure 2.1), and thus demonstrably registers A's attempt to initiate a transfer. Her left hand is free, resting on her lap and close to the bun, but she does not take it. Turning her head back to the road without taking the object, she minimizes the trouble source, encourages A to eat the bun anyway, and gives a reason for not taking the bun with "> Well it was only< a little tiny bit, it's probably gone now." (1. 10).

Following her resistance, A maintains his proffer and moves the bun around, thus treating the absence of an embodied response as noticeable (see Schegloff 1968). By upgrading his proffer in this manner, he insists and thereby claims his agency to not eat the bun despite B's non-compliance to the proffer. He also verbally re-asserts the trouble source with "No, it's no::t." (1. 12, Figure 2.2). He finally gives up on pursuing a physical response from her by taking the bun away from her and towards the front of the car to get rid of the bun himself. His final plea, "Please, I don't want it." (1. 13), retrospectively shows that his attempt to give her the bun was also a request for authorization not to eat it. B does not answer through talk, she follows with gaze where he leaves the bun, and finally agrees ("o Okay. ${ }^{\text {"', }}, 1.14$, "O$\left.O(h) k(h) a y .{ }^{\circ} ", 1.16\right)$, giving up on trying to make her son eat his bun.

In sum, A projects a transfer between the first complaint about the bun and an explicit rejection to eat it. The proffer thus takes part in the progressive explicitation of a request. Not responding to the initiation of the object transfer is a resource for the mother to not align immediately with her son's request and to try and negotiate his eating of the bun. The mother's non-response does not straightforwardly reject the ongoing attempt, but rather postpones the child's abandoning of the bun. In this way, it opens up a space for negotiation. For the child, maintaining the proffer is a resource to re-assert his agency and maintain the negotiation, instead of immediately complying with the mother's rejection.

In Excerpts 1 and 2, the participant initially holding the object initiates both the request sequence for B to inspect the object (Excerpt 1) and for B to take the object away (Excerpt 2) - and the object transfer, although in the latter, the transfer is not completed. We have shown that the embodied action of proffering the object towards B contributes to the overall progression of the activity by making sequentially relevant that B take the object. Furthermore, we have shown that the recipient can either align with the proffer by taking the object immediately, or negotiate the trajectory of action and thus display her agency.

In the next section, we analyze two excerpts where - similarly with Excerpts 1 and 2 - the organization of the action sequence and the object transfer overlap. However, in Excerpts 3 and 4, it is B who initiates the course of action with a verbal and/or embodied request for the object. Emphasizing the contrast between the two excerpts, both in how the object is made available and in the timing of B's response, we show that co-participants can make objects available to one another in ways that put more or less demand on the recipient, and that such variations in sequential implicativeness are resources to adjust one's participation in the joint course of action. 


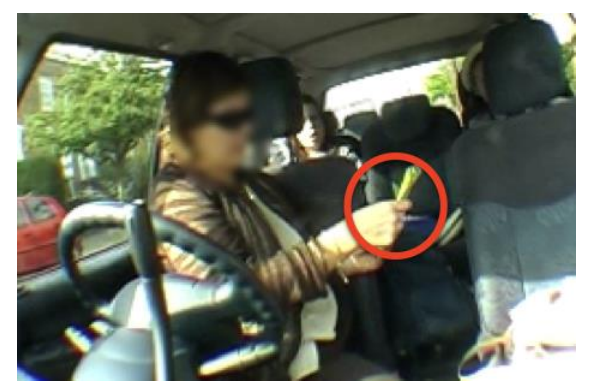

Figure 3.4

With "Well you:rs aren't (0.4) crisps are they if they're corn puffs, >or whatever, <" (lines 1-3), B discards C's packet of corn puffs as a potential source of information in the joint activity of discovering

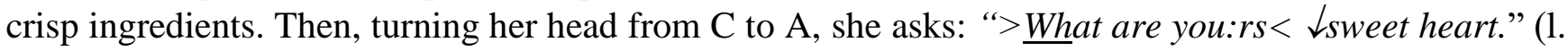
4). A answers with "OThey're crisps. " (1. 6), after which the mother asks to see the packet: "Can we see what they're Tmade of?" (1. 8). A immediately responds by proffering her packet in B's direction (Figure 3.2), and almost simultaneously B takes her right hand off the driving wheel and extends it in the packet's direction (Figure 3.3). She takes the packet, turns slightly away (Figure 3.4), and with "H(h)ere w(h)e are(h) hh. In Tgredients." (1. 10), she acknowledges receiving the object and starts reading the packet.

The request sequence is initiated by the mother's question on line 7 . Considering that a moment before, $\mathrm{C}$ has read the list of ingredients on her packet, and that the participants share the knowledge of A's limited reading skills, this question can be understood as a suggestion (Couper-Kuhlen 2014) that the mother read the list of ingredients from the packet for the participants' common benefit. The use of the pronoun " $w e$ " emphasizes the collective orientation of the suggested action. The way A responds by immediately proffering the packet displays her understanding of the suggestion and her alignment with it; she cooperates and agrees to give her packet in order to participate in the activity. Conversely, that B expects A to give her the packet shows that the 'give' is a relevant and expected response to the question. But by keeping her arm close to herself and not to the object before it is proffered, B puts little demand on A to give it, and orients to A's agency in the activity. In other words, this distribution and transfer organization allow A to exert her agency and enact her ownership of the object, and since she complies to the verbal request, to enable the unproblematic progression of the activity. Compared to Zinken's (2015) dinner participants, who tend to display high entitlement over requested objects by accompanying their verbal request with an arm stretch to the object, mother and daughter here orient to the girl's sole control over her packet of crisps.

In Excerpt 4, the sequence is initiated in a similar way: B asks for an object and A makes the object available to B. However, both the way in which the object is made available, and the moment B takes the object markedly differ from Excerpt 3. Excerpt 4 involves three friends journeying in a car, with a third participant (C) in the back seat only addressed as a recipient. Prior to the beginning of the excerpt, the driver (B) has said that the car needs petrol. He has pointed towards the glove compartment in front of the front-seat passenger (A) (data not shown). A treats the pointing as a request for an object: he opens the glove compartment and visibly searches inside it. A new activity is initiated which involves all the car passengers: filling the car with petrol.

\section{Excerpt 4 (Habitable Cars corpus)}

$01 \mathrm{~A} \quad$ [You know this card-]

02 B [You have the: credit] card. 
$03 \quad(0.8)$

$05 \quad(0.6)$

06 A Ne:, ne:h.

$07 \quad(0.4)$

08 A It's like e::::rm,

$09 \quad(0.6)$

$10 \mathrm{~A}$ It's like rental cars.

$11 \quad(2.1)^{\wedge}(0.2) \#$

B $\quad->\wedge$ pulls handbrake, turns head to gas pump

fig \#fig.4.1

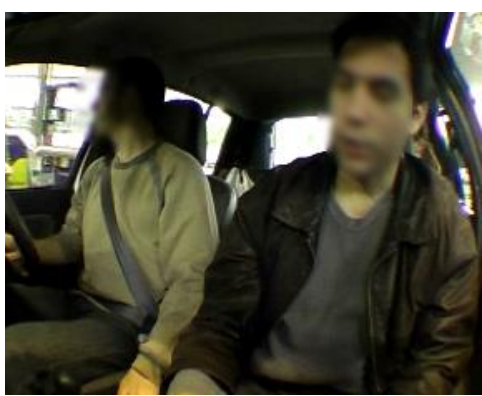

Figure 4.1

12 A *Actually I *was telling*^\#*Maria about* this*,

A *turns head to the right

A

B

A

A

fig

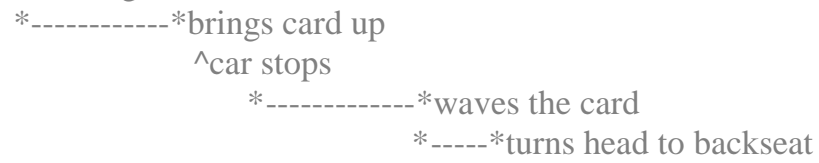

\#fig.4.2

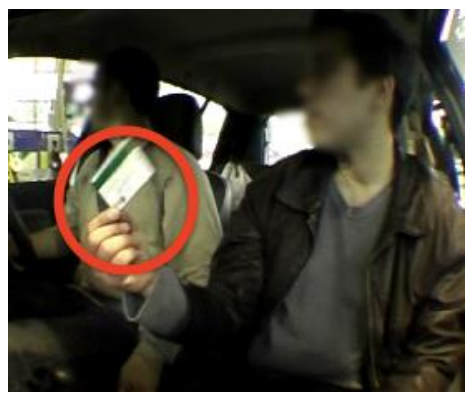

Figure 4.2

$13 \wedge *(0.3)^{\wedge}(0.2)$

B $\wedge$------^turns head to card

A *waves the card

14 A $\wedge *$ e::r\# *scheme.

B $\wedge$ releases seatbelt

A *--.--**turns to B

fig \#fig.4.3 


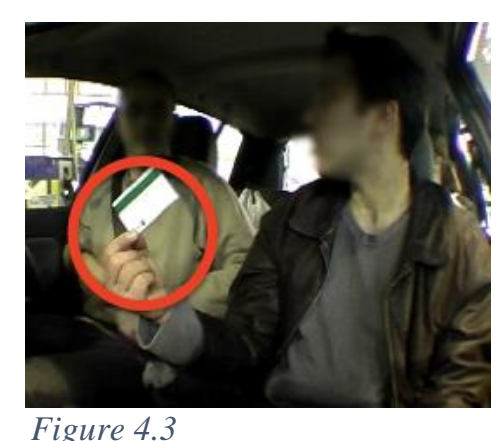

15

$(0.7)^{\wedge} \#(0.2)$

B $\wedge$ takes the card

Fig \#fig.4.4

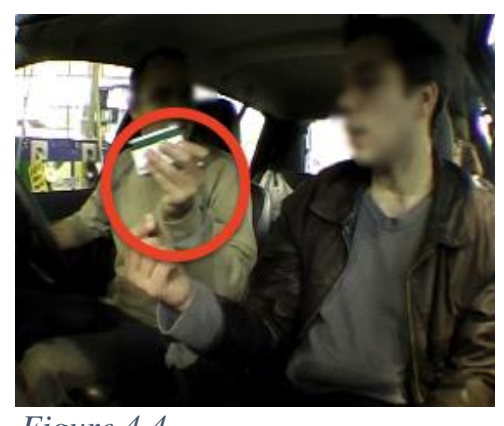

16 A I'll *tell Alexia. ${ }^{\wedge}$

A * * points to backseat passenger with thumb

B

$\wedge$ opens door

In lines 1-2, overlapping with each other, A and B for the first time explicitly refer to the object they are jointly oriented to as central in the unfolding course of action. While A's turn "You know this card-" (1. 1) seems to project a telling, but is abandoned to give the floor to the other speaker, B specifies his earlier embodied request (data not shown) with "You have the: credit card" (1. 2), asking A for the card that will be used to pay the petrol. The changing, visible environment around the car is an indication for B to organize his search (Laurier 2013; Haddington 2012). Seeing that the car is entering the gas station at approximately this moment, he can anticipate that the driver does not need the card immediately but will in a short while. As B invites A to pursue his line of talk (1. 4), A with a positive, repeated answer (1. 6) ${ }^{6}$ (Stivers 2004) confirms that he will, and shows that he was going to anyway. He resumes with "It's like e:::rm, (0.6) It's like rental cars" (lines 8-10) while searching for the card. Meanwhile, they reach the gas pump and B pulls the handbrake and turns his head to the pump (Figure 4.1). Turning his head in the same direction, A initiates a new turn, brings the payment card up in the middle of the car compartment (Figure 4.2), waves it, and turns his head to the backseat: "Actually I was telling Maria about this, (0.5) e::r scheme." (1. 12). The object becomes visible and physically accessible to all just as they arrive at the gas pump. At the same time, A's turn-at-talk reframes his upcoming telling, and situates the topic for the participant on the backseat: he weaves together the physical trajectory of the object and the conversational activity. "This scheme" does not refer to the card itself, but to an organizational entity of which the card as a material object represents. Meanwhile, the driver turns his head to the card, unfastens his seatbelt (Figure 4.3), and takes the card (Figure 4.4). With "I'll tell Alexia" (1. 16, referring to C), A releases $\mathrm{B}$ from the responsibility to participate in the telling and provides him the possibility to exit and fill up the car. 
In this example, by making the card visually salient between the front seats at the moment they reach the pump, A makes the card available to B in a way that contributes to the joint activity - filling the car tank - in a timely manner. In addition to this, he adjusts to B's unfolding actions which are constrained by the driving, but also projectable and anticipated in relation to filling up the car and paying the petrol. In other words, Excerpt 4 bears some similarities with the passing of objects in surgical theatres: a subsequent action which requires the object, and thus the passing of an object, is projectable and projected.

However, unlike scrub nurses who work in silence and rely on visual resources to maintain the relevance of a proffer while avoiding to place a demand on surgeons (Heath et al., 2018), in Excerpt 4, A makes the object's presence within B's reach unproblematic and even justified by turning it into a conversational topic. By creating joint attention to the object for use both as a tangible object and as a topic for conversation, he does not put a demand on B for him to take the card there and then, so that his holding the card between himself and B is not treated as sequentially implicative. B takes the card three seconds later, and during these three seconds A does not orient in any way to a response, a take, as missing. He only releases the card when B takes it, thus adjusting to B's constraints and agency to take the card whenever he wants, needs to, or can.

In this section, the examples have shown A making an object available to B in response to B's verbal request for it. In Excerpt 3, A's movement with the object is immediately responded to as a proffer initiating an object transfer, which previous research shows is a typical format in requests for objects. However, Excerpt 4 shows how B can be seen to "do more" to achieve the actual object transfer by reaching out for it not when it is made available, that is, not in response to an action by B. In this case, A's conduct with the object is treated as non-sequentially implicative. The next section explores this organization in more depth. In Excerpts 5 and 6, we show how sequence organization and transfer organization can intersect: A initiates the sequence, makes the object available without placing any demand on B, and B initiates the transfer. The participants thereby use the embodied actions involved in object transfers as flexible resources to display agency in the unfolding activity. In these cases, transfers tend to mark a shift in participants' involvement, their re-alignment in a joint course of action, and an upgraded form of intersubjectivity.

\section{TRANSFER INITIATION AS A FLEXIBLE RESOURCE FOR THE RECIPIENT TO MARK REALIGNMENT AND PROGRESS INTERACTION}

Excerpt 5 involves two biochemists working side by side at the bench, each on a separate task but involved in a larger, joint activity which consists of mixing substances to create base products for the upcoming months. B has just completed a preparation. In Excerpt 5, A gives instructions to B for the next preparation. A is holding a small bottle that plays an important role in the instruction-giving. Just prior to the example, B has named the content (data not shown). The participants are also browsing a paper document to find out which product they should mix the content with.

Excerpt 5 (Biochemistry Lab corpus)

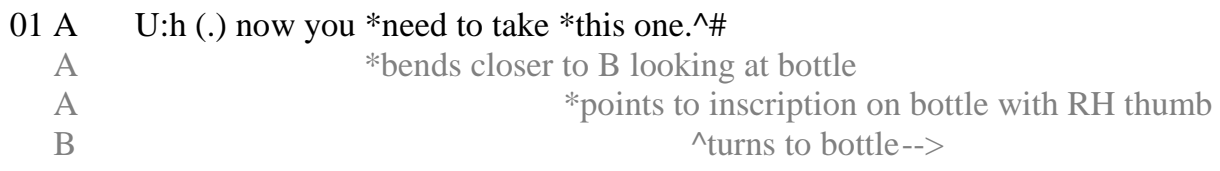


fig

02

B

A

A

B

A

A

$03 \mathrm{~B}$

*[Go] there. ${ }^{\wedge} \#$

A *turns gaze to bottle, moves it closer to $\mathrm{B}$

B

fig

$(1.2)^{\wedge *(}(0.5)^{\wedge}(0.3)^{*}(0.3)^{\wedge}(0.2)^{*}(0.2)^{*}$

$\wedge$------^briefly turns head to doc, back to A -->*points (apex)

$\wedge$ pushes away from bench

\#fig.5.2

\#fig.5.1

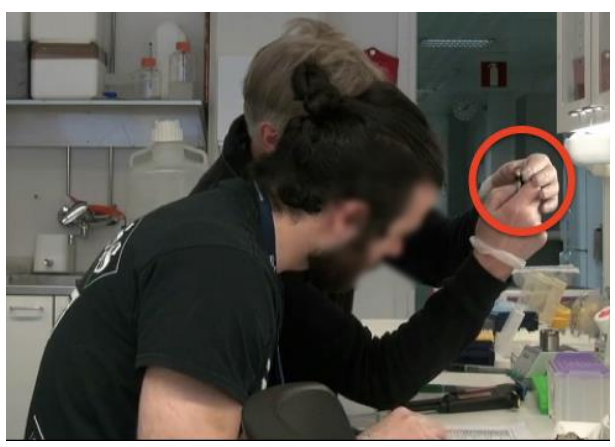

Figure 5.1

*leans back, turns head and upper body to space behind-->

*takes RH off of bottle, points-->

$\wedge$ turns head other way round (R), following A's pointing

*retracts pointing-->

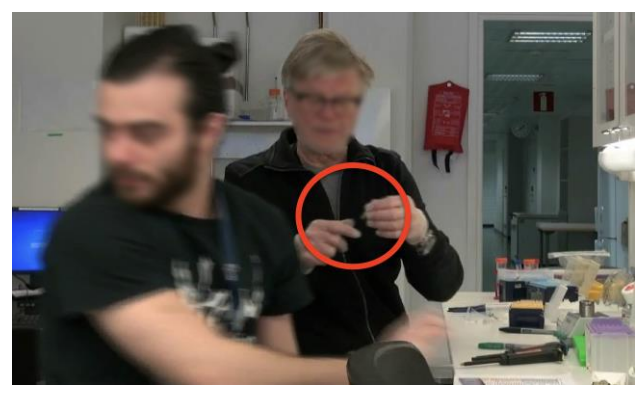

Figure 5.2

$05 \quad(0.2)^{*}(0.2)^{\wedge}(0.2)^{*}(0.3) \#(0.2)$

A $\quad->*$ follows B's movement with gaze, $\mathrm{RH}$ on bottle

B

$\wedge$ turns around, raises LH (to bottle)

*takes LH off of bottle, proffers bottle with RH

fig

\#fig.5.3

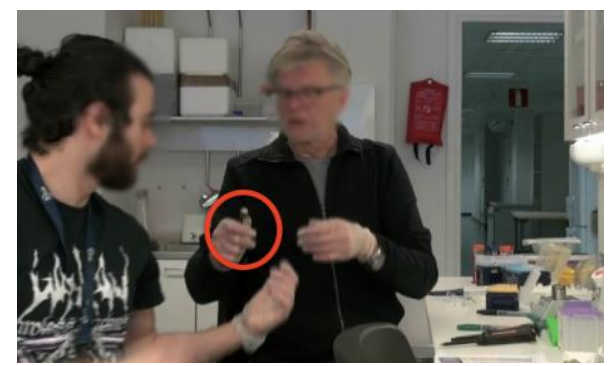

Figure 5.3

$06 \mathrm{~A}$ Try to ${ }^{\wedge * \#}$ find it there.

B Atakes bottle with RH, turns away-->

A *releases bottle, turns away 


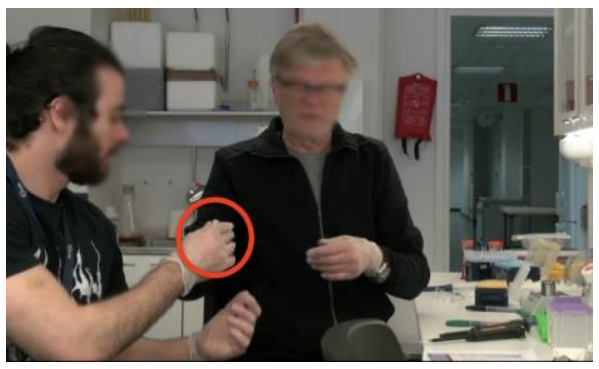

Figure 5.4

A initiates a new sequence in the activity with the directive: "U:h (.) now you need to take this one." (1. 1). At the same time, he leans sideways toward B looking at the bottle. He brings the bottle closer to B's visual field, points to a small inscription on the bottle and refers to the inscription with "this one." (Figure 5.1). A's turn-at-talk and embodied conduct, first, invite B to read the inscription on the bottle and, second, function as an instruction for B to find the product associated with this inscription. Finding the associated product is a necessary step that B needs to accomplish before he can proceed to the next preparation. Next, B responds with a brief head turn to the bottle (1. 1), but does not in any way display understanding of the instruction or produce any sort of uptake. An important thing to notice is that A holds the bottle between him and B from his initial directive onward, so that it is constantly available for $\mathrm{B}$ to see and to take. 1.2 seconds after his directive in 1. 1, and in an attempt to clarify the instruction that $\mathrm{B}$ has not responded to, A leans back, turns around, and points to the bench behind them where other products are available (1. 2). In response to A's pointing gesture, B turns his head and upper body to the right, displaying an effort to align, but then produces an open-class repair initiator (Drew, 1997) (" $\mathrm{mm}$ ?", 1. 3) which shows he does not actually understand the instruction. The discrepancy between, on the one hand, this explicit lack of understanding and, on the other hand, his embodied compliance shows an emerging breach in intersubjectivity and joint involvement in a course of action.

As B is turning away, A looks at the bottle and moves it closer to B, thus emphasizing its physical availability (1. 4, Figure 5.2), and produces another directive: "Go there" (1. 4). However, at this point B has turned away from A and cannot see A's movement with the object. Immediately after this, B stops the movement towards the bench behind them, turns around to face A and extends his left hand towards the bottle (1. 14-15, Figure 5.3), thus indicating that he will take the bottle. At the same time, A proffers the bottle to B while moving it from his left to his right hand (Figure 5.3): he was expecting B to take the bottle and is ready for it. After this, as A clarifies his initial instruction with "Try to find it there" (1. 6), B takes the bottle (Figure 5.4) and again turns around to the bench behind him.

From the moment A starts to show the bottle and instruct B, he holds the bottle so that it is accessible for B to take, but that B does not take the object is not oriented to as a missing transfer. By not requiring B to take the bottle, A lets B progress and implement the instructed action independently, with or without the bottle. Meanwhile, through his successive directives in lines 11 and 18, which specify the initial instruction, A orients to and attempts to remediate B's apparent lack of understanding. Reciprocally, B takes the object only once he has fully understood how holding the object may be relevant to follow the instruction: he needs to the take bottle in A's hand and check the inscription on the bottle in order to find the relevant object on the bench he was approaching. The moment he initiates the object transfer marks the moment he begins to actually follow A's instruction and to substantially "do more" to progress the joint course of action. His first left-hand extension is a harbinger of his actual, right-handed take aiming for B to prepare for the object transfer, which shows that it is not in response to A's conduct that B takes 
the object. B's actions in taking the bottle thus enact his agency and are independently organized relative to the instruction-compliance sequence.

In the last excerpt, two laboratory scientists are working separately in a big room, in a continuing state of incipient talk (Schegloff \& Sacks 1973: 262; Szymanski 1999; Szymanski et al. 2006). B is wearing earphones. As the transcript begins, A is approaching B from behind holding a microtube in front of him and looking at it. B demonstrably notices A by turning to him just before A initiates a question about this microtube: "Is it normal that Hoechst ${ }^{7}$ is like this?" (1. 1).

\section{Excerpt 6 (Biochemistry Lab corpus)}
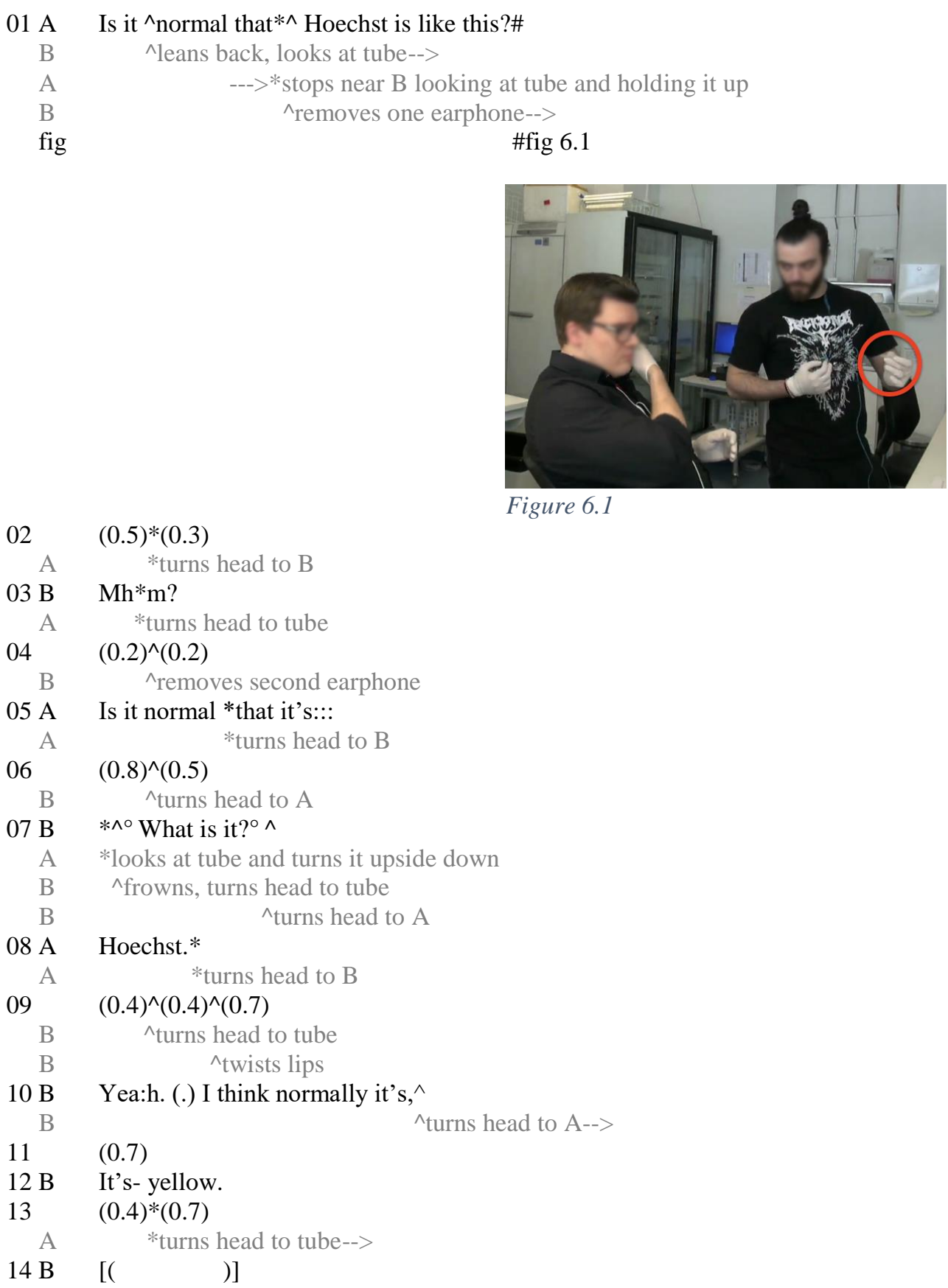
15 A [No I mean it]'s::, usually it's more liquid.\# fig

\#fig 6.2

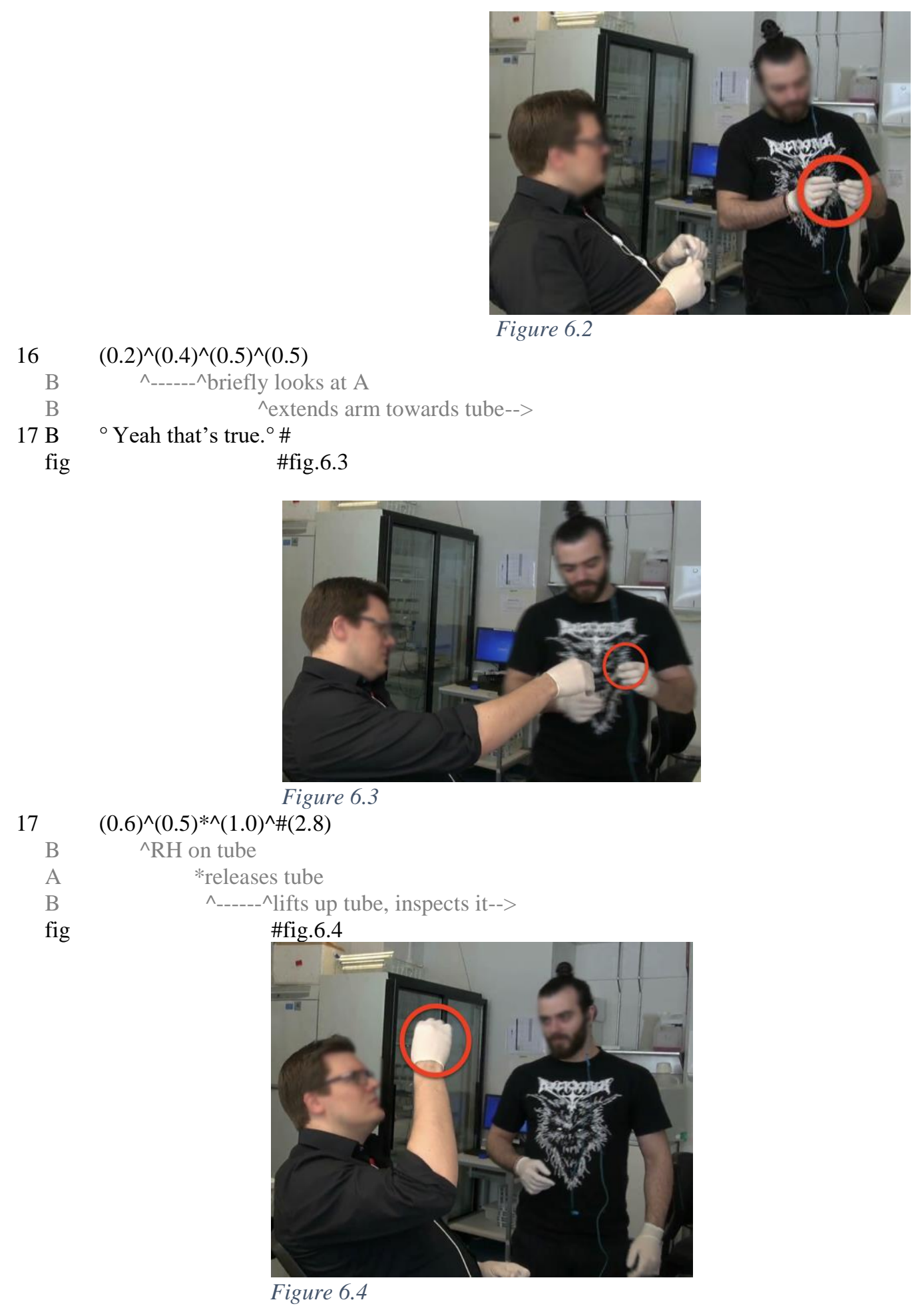

After asking about the microtube "Is it normal that Hoechst is like this?" (1. 1), A stops near B, briefly keeps the microtube stable in A's field of vision, and then turns his head from the tube to B (Figure 6.1). B produces an open-class repair initiator (Drew, 1997) "Mhm?" (1. 3) indicating a hearing problem, and 
continues to remove his earphones (1. 1 and 4). A reformulates his initial question (1. 5) and at the same time moves and shakes the tube. B then asks "What is it?" (1. 7), which A answers by repeating the product's name ("Hoechst", 1. 8). During this exchange, their gazes shift between the tube and each other. After a 1.5-second silence, B initiates a hesitant answer that refers to the color of the substance: "Yea: $h$ (.) I think normally it's, (0.7) it's- yellow." (lines 10-12). A rejects this answer: "No I mean it's.:, usually it's more liquid" (1. 15, Figure 6.2), referring instead to the texture of the substance, which explains why he has been moving the tube all along: he has been trying to make B see the product's unusual texture.

A 1.6-second silence follows, during which B looks at the tube, briefly at A, at the tube again, and extends his arm to the tube right before agreeing with A: "Yeah that's true." (1. 17). During this turn, A moves his body closer to B and removes his right hand to give B better access to the tube, so that B's hand can reach the tube shortly after (Figure 6.3). B takes the tube, lifts it up and inspects it (Figure 6.4).

From the beginning of the sequence until its turning point around "Yeah that's true", by shifting his gaze from the microtube to his co-participant, B displays not only recipiency but an effort to understand and attend to A's question. Indeed, misalignments have followed one another: with hearing (1. 3), with identifying the product (1. 7), and about the feature of the product to focus on (lines 10-12). Furthermore, the microtube has been within B's reach from the beginning, but he has treated A's conduct with it as a 'show': he visibly displays himself as looking at the microtube. B's agreement "Yeah that's true." (1. 17) and that he takes the object (1. 30) mark the end of the last of these problems; the co-participants have reached alignment and repaired the glitch in intersubjective understanding. By taking the microtube at this point - something which talk cannot achieve in the same way - B also commits to A's interactional project, which now becomes a joint project with the object. By initiating the transfer, B not only displays that he has joined A's perspective on the object, he also upgrades his involvement in A's interactional project that they investigate the problem together. B can treat A's conduct as a 'show' or a 'give' - a flexibility intrinsic to object proffers - to display his agency in the progressive build-up of a joint project and course of action.

\section{CONCLUSION}

When social participants are jointly involved in an activity with an object, who is holding the object and thus how it can be handed over to a co-participant - or not - are crucial resources for the participants in making sense of what we are doing together, and in building their social relationship. As part of EMCA's recent interest in objects in interaction, how participants hand over objects to one another has been studied either in interactions involving children or among medical staff following procedures. The present article complements previous studies by focusing on situations where co-workers or relatives are involved in emergent, joint courses of actions. We this focus, we shed light on what can be accomplished specifically through embodied conduct with the object.

We have shown that manual actions with and around objects are flexible resources to progress a course of action, influence its trajectory and display agency. Building on existing studies of requests for objects, we showed (a), with two examples where the same participant initiates the offer sequence and the transfer, how a recipient can align or resist to a course of action by taking or not taking the object. Zooming in on the sequential (non-)implicativeness of object proffers with examples where the transfer is initiated in response to a request for the object, we also showed (b) the difference between an object proffer initiating a transfer, and a way of making an object available, finely adjusted to the ongoing activity, which makes a transfer possible but not sequentially relevant, and thereby does not demand from the recipient that she take the object now. Thereby, it was also shown that one participant "does more" in terms of embodied action for the transfer to happen: either the one proffering the object or the one 
taking the available object. Then, building on the former findings, the last section focused on situations where the transfer organization and that of the course of action clearly intersect. An intersubjective breach emerges while the object is available and talked about, so that (c) the transfer initiation enacts a particular form of agency, and marks participants' realignment and upgraded involvement in the joint course of action, the repair of intersubjectivity.

In all, we hope to have demonstrated that the embodied actions involved in object transfers, through the way they are shaped and embedded in talk and other semiotic fields, are meaningful resources for either participant to display agency in a joint course of action.

\section{Endnotes}

${ }^{1}$ The authors would like to thank two anonymous reviewers for their invaluable insights and help to improve this manuscript, all remaining limitations remain ours. We would also like to thank Gene Lerner, whose visit to Oulu in 2016 partly prompted the present research. Finally, we would like to thank Eric Laurier for letting us use the Habitable Cars corpus, and for his generous companionship through the years.

${ }^{2}$ This line of research will be taken up in a co-edited volume by Tuncer, Licoppe \& Haddington in Discourse and Conversation Analysis.

${ }^{3}$ For a tutorial, see https://franzoesistik.philhist.unibas.ch/fileadmin/user_upload/franzoesistik/mondada_multimodal_conventions.pdf

${ }^{4}$ The turn construction in Finnish is such that "too" can be heard to refer to the addressee as in "You too take a look at this one", and not to the tube as in "Take a look at this other tube".

${ }^{5}$ The two daughters are not visible in the images. However, their arms can be seen when the objects are passed to or from the front seat.

${ }^{6}$ In Greek, the co-participants' native langue, "Naî", transcribed here as "Ne", means "yes".

${ }^{7}$ Hoechst is a cell-staining product commonly used in biochemistry. Laboratories receive a base product which they dissolve in various concentrations to obtain the products they will actually use. In addition to B's superior expertise about the product displayed in A's initial question and throughout the excerpt, we know from fieldwork that B has been preparing the series to which this tube belongs. A found unclear the inscriptions B had made on the tube, which also explains why he went to him with this question.

\section{References}

Bezemer, Jeff; Murtagh, Ged; Cope, Alexandra; Kress, Gunther \& Kneebone, Roger (2011). 'Scissors, please' The practical accomplishment of surgical work in the operating theatre. Symbolic Interaction 34(3), 731-745.

Cekaite, Asta (2015). The coordination of talk and touch in adults' directives to children: Talk and social control. Research on Language and Social Interaction 48(2), 162-175.

Couper-Kuhlen, Elizabeth (2014). What Does Grammar Tell Us About Action? Pragmatics 24(3), 623647.

Deppermann, Arnulf (2013). Multimodal interaction from a conversation analytic perspective. Journal of Pragmatics 46(1): 1-7.

Dixon, Sally (2015). Gimme! Gimme! Gimme: Object requests, ownership and entitlement in a children's play session. Journal of Pragmatics 82: 39-51.

Drew, Paul (1997). 'Open class' repair initiators in response to sequential sources of troubles in conversation. Journal of Pragmatics 28(1): 69-101.

Ekström, Anna, \& Oskar Lindwall (2014). To follow the materials. The detection, diagnosis and correction of mistakes in craft education. In M. Nevile, P. Haddington, T. Heinemann \& M. 
Rauniomaa (Eds.), Interacting with objects: Language, materiality, and social activity, 227-247. Amsterdam: John Benjamins.

Fasulo, Alessandra, \& Chiara Monzoni (2009). Assessing mutable objects: A multimodal analysis. Research on Language and Social Interaction 42(4): 362-376.

Fox, Barbara, \& Trine Heinemann (2015). The alignment of manual and verbal displays in requests for the repair of an object. Research on Language and Social Interaction 48(3): 342-362.

Goodwin, Charles (1994). Professional Vision. American Anthropologist 96 (3): 606-33.

(1997). The blackness of black. Color categories as situated practice. In L.B. Resnick, R. Saljö, C. Pontecorvo \& B. Burge Discourse, tools and reasoning: Essays on situated cognition, 111-140. Berlin: Springer.

(2000). Action and embodiment within situated human interaction. Journal of Pragmatics 32 (10): 1489-1522.

Haddington, Pentti (2012). Movement in action: Initiating social navigation in cars. Semiotica 191: $137-$ 167

Heath, Christian; Paul Luff; Marcus Sanchez-Svensson; \& Maxim Nicholls (2018). Exchanging implements: The micro-materialities of multidisciplinary work in the operating theatre. Sociology of Health \& Illness 40(2), 297-313.

Hindmarsh, Jonathan, \& Christian Heath (2000). Sharing the tools of the trade. Journal of Contemporary Ethnography 29(5): 523-562.

Hindmarsh, Jonathan, \& Alison Pilnick (2007). Knowing bodies at work: Embodiment and Ephemeral teamwork in anaesthesia. Organization Studies 28(9): 1395-1416.

Horlacher, Sylvie (forthcoming). Workplace asymmetries and object-passing in hair salons. In Dennis Day, \& Johannes Wagner (eds.), Objects, Bodies and Work Practice. Multilingual Matters. Objects at Work Series.

Jefferson, Gail (2004). Glossary of transcript symbols with an introduction. In G.H Lerner (Ed.) Conversation analysis: Studies from the first generation, 13-31. Philadelphia: John Benjamins.

Jones, Sarah E, \& Don H Zimmermann (2003). A child's point and the achievement of intentionality. Gesture 3(2): 155-185.

Kendrick, Kendrick H, \& Paul Drew (2016). Recruitment: Offers, requests, and the organization of assistance in interaction. Research on Language and Social Interaction 49(1): 1-19.

Kidwell, Mardi (2013). Interaction among children. In Tanya Stivers, \& Jack Sidnell (eds.), The handbook of conversation analysis, 511-532. Malden, MA: Wiley-Blackwell.

----------- \& Don H Zimmermann (2007). Joint attention as action. Journal of Pragmatics 39: $592-611$.

Knorr-Cetina, Karin (1997). Sociality with objects. Social relations in postsocial knowledge societies. Theory, Culture \& Society 14(4): 1-30.

Korkiakangas, Tehri; Weldon, Sharon-Marie; Bezemer, Jeff \& Kneebone, Roger (2014). Nurse-surgeon object transfer: Video analysis of communication and situation awareness in the operating theatre. International Journal of Nursing Studies 51(9), 1195-1206.

Latour, Bruno (1993). La Clef de Berlin, et autres Leçons d'un Amateur de Sciences. Paris, La Découverte.

Laurier, Eric (2013). Before, in and after: Cars making their way through roundabouts. In Lorenza Mondada; Pentti Haddington, \& Maurice Nevile (eds.), Interaction and Mobility: Language and the Body in Motion, 210-242. Berlin: De Gruyter.

LeBaron, Curtis, \& Jürgen Streeck (1997). Built space and the interactional framing of experience during a murder interrogation. Human Studies 20: 1-25. 
Lerner, Gene, \& Don H Zimmermann (2003). Action and the appearance of action in the conduct of very young children. In P. Glenn, C. LeBaron \& J. Mandelbaum (eds.), Studies in language and social interaction, 441-457. Mahwah, NJ: Lawrence Erlbaum.

Mondada, Lorenza (2018). Multiple temporalities of language and body in interaction: Challenges for transcribing multimodality. Research on Language and Social Interaction 51(1), 85-106.

Nevile, Maurice; Pentti Haddington; Trine Heinemann, \& Mirka Rauniomaa (eds.) (2014). Interacting with objects: Language, materiality, and social activity. Amsterdam: John Benjamins.

Nishizaka, Aug (2011). Touch without vision: Referential practice in a non-technological environment. Journal of Pragmatics 43, 504-520.

Ogiermann, Eva (2015a). Object requests: Rights and obligations surrounding object possession and object transfer. Journal of Pragmatics 82: 1-4.

-------- (2015b). In-directness in Polish children's requests at the dinner table. Journal of Pragmatics 82: 67-82.

Rauniomaa, Mirka, \& Tiina Keisanen (2012). Two multimodal formats for responding to requests. Journal of Pragmatics 44(6-7): 829-842.

Raymond, Chase Wesley, \& Tanya Stivers (2016). The omnirelevance of accountability. In Jeffrey D. Robinson (ed.), Accountability in Social Interaction, 321-353. Oxford University Press.

Robles, Jessica (2012). Troubles with assessments in gifting occasions. Discourse Studies 14(6): 753777.

Rossi, Giovanni (2014). When do people not use language to make requests? In P. Drew \& E. CouperKuhlen (Eds.), Requesting in social interaction, 303-334. Amsterdam, John Benjamins Publishing Company.

Sanchez-Svensson, Marcus; Heath, Christian \& Luff, Paul (2007). Instrumental action: the timely exchange of implements during surgical operations. In ECSCW'07: Proceedings of the tenth European Conference on Computer Supported Cooperative Work, 41-60. Bannon, L. Wagner, I., Gutwin, C., Harper, R \& Schmidt, K. (Eds.), 24-28 September 2007, Limerick, Ireland.

Schegloff, Emanuel A (1968). Sequencing in conversational openings. American Anthropologist 79(6): 1075-1095.

(2007). Sequence organization in interaction: A primer in conversation analysis. Cambridge, New York: Cambridge University Press.

--------------, \& Harvey Sacks (1973). Opening up closings. Semiotica 7(4): 289-327.

Scollon, Ron (2001). Mediated discourse: The nexus of practice. London: Routledge.

Steensig, Jakob, \& Trine Heinemann (2013). When 'yes' is not enough - as an answer to a yes/no question. In Beatrice S. Reed \& Geoffrey Raymond (Eds.), Units of talk: Units of action, 213-48. Amsterdam: John Benjamins.

Stivers, Tanya (2004). "No no no" and other types of multiple sayings in social interaction. Human Communication Research 30(2), 260-293.

Streeck, Jürgen (1996). How to do things with things. Objets trouvés and symbolization. Human Studies 19: $365-384$.

-------------; Charles Goodwin; \& Curtis LeBaron (eds.) (2011). Embodied interaction: Language and the body in the material world. Cambridge: Cambridge University Press.

Szymanski, Margaret H. (1999). Re-engaging and dis-engaging talk in activity. Language in Society 28(1): 1-23.

---------; Erik Vinkhuyzen; Paul Aoki, \& Allison Woodruff (2006). Organizing a remote state of incipient talk: Push-to-talk mobile radio interaction. Language in Society 35, 393-418.

Takada, Akira, \& Tomoko Endo (2015). Object transfer in request-accept sequence in Japanese caregiver-child interactions. Journal of Pragmatics 82: 52-66. 
Tuncer, Sylvaine; Christian Licoppe; \& Pentti Haddington (Eds.) (forth.). Special issue: Object-centred sequences in interaction: generating knowledge about objects in specialised activities. Gesprächsfroschung.

Tuncer, Sylvaine, \& Pentti Haddington (forth.). Looking at and seeing objects: Instructed vision and collaboration in the laboratory. Gesprächsfroschung.

Valsiner, Jaan (2000). Culture and Human Development. An introduction. London: Sage Publications.

Weilenmann, Alexandra, \& Gustav Lymer (2014). Incidental and essential objects in interaction. Paper documents in journalistic work. In Interacting with objects: Language, materiality, and social activity, 319-337. op cit.

Wootton, Anthony J. (1994). Object transfer, intersubjectivity and third position repair: Early developmental observations of one child. Journal of Child Language, 21(3): 543-564.

Zinken, Jörg (2015). Contingent control over shared goods. 'Can I have x' requests in British English informal interaction. Journal of Pragmatics 82: 23-38.

---------, \& Eva Ogiermann (2013). Responsibility and action: Invariants and diversity in requests for objects in British English and Polish interaction. Research on Language and Social Interaction 46(3): 256-276. 